\title{
Social tension as precursor of large damaging earthquake: legend or reality?
}

\author{
O. Molchanov \\ Institute of the Physics of the Earth, Russian Acad. of Sci., Bolshaya Gruzinskaya 10, 123995, Moscow D-242, Russia \\ Received: 18 June 2008 - Revised: 22 September 2008 - Accepted: 22 September 2008 - Published: 24 November 2008
}

\begin{abstract}
Using case study of earthquake (EQ) activity and war conflicts in Caucasus during 1975-2002 time interval and correlation analysis of global distribution of damaging EQs and war-related social tension during 1901-2005 period we conclude:
\end{abstract}

- There is a statistically reliable increase of social tension several years (or several months in case study) before damaging EQs,

- There is evident decrease of social tension several years after damaging EQs, probably due to society consolidation,

- Preseismic effect is absent for the large EQs in unpopulated areas,

- There is some factual background for legendary belief in Almighty retribution for social abnormal behavior.

\section{Introduction}

Impact of catastrophic earthquake (hereafter EQ) on social life is more or less well-known. Large EQ in populated area leads usually to the direct fatalities and injuries, destruction of electricity, gas and traffic networks, endangering of the food and water supply, tsunami and fires can be broken out and economic damage can be great. Furthermore the social structure of society can be seriously affected by countless number of homeless people and occurrence of looting. We can conclude that an evident social tension is appearing as a consequence of the damaging EQ.
However at least sometimes the social tension preceding EQ catastrophe can be also supposed. Personally I met this idea during scientific meeting devoted to 15 year anniversary of famous Spitak EQ in Armenia. Some people there consider that EQ as a result of Karabakh civil war which begins about one year before the EQ. The idea is clear reminiscence of ancient superstition that any natural catastrophe is God's punishment for the people sins. For example in complicated hierarchy of the Greek gods the first place was belonged to Zeus, who was responsible for skies and thunderstorms, but next place was for his brother Poseidon, who was the god of sea and earthquakes. So there was clear separation between them in frightening methods: Zeus threw out the lightnings but Poseidon produced the earthquakes. Probably more modern point of view is considering of preceding increase in social tension as precursor of EQ like well-discussed precursors in abnormal animal behavior (e.g. Tributsch, 1983). But first of all we need to prove that the effect exists indeed. Here we try to provide some evidence for it.

\section{Local EQ statistics in Caucasus}

Now we are going to estimate EQ activity in connection with social tension in Caucasus area. Because of any positive science begins from measuring we have rather difficult task how to find a quantitative definition of the social tension. Is it rate of political demonstrations, market index, and rate of criminality, rate of suicides or some complex index? While such a clear definition is absent in sociology, we can simply believe by intuition that the social tension is increasing during the local military conflicts or internal civil wars. Concerning recent situation in Caucasus we can distinguish two time intervals and specific areas:

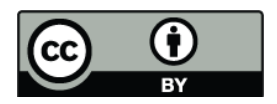

Correspondence to: O. Molchanov

(oleg@molchanov.org)

Published by Copernicus Publications on behalf of the European Geosciences Union. 


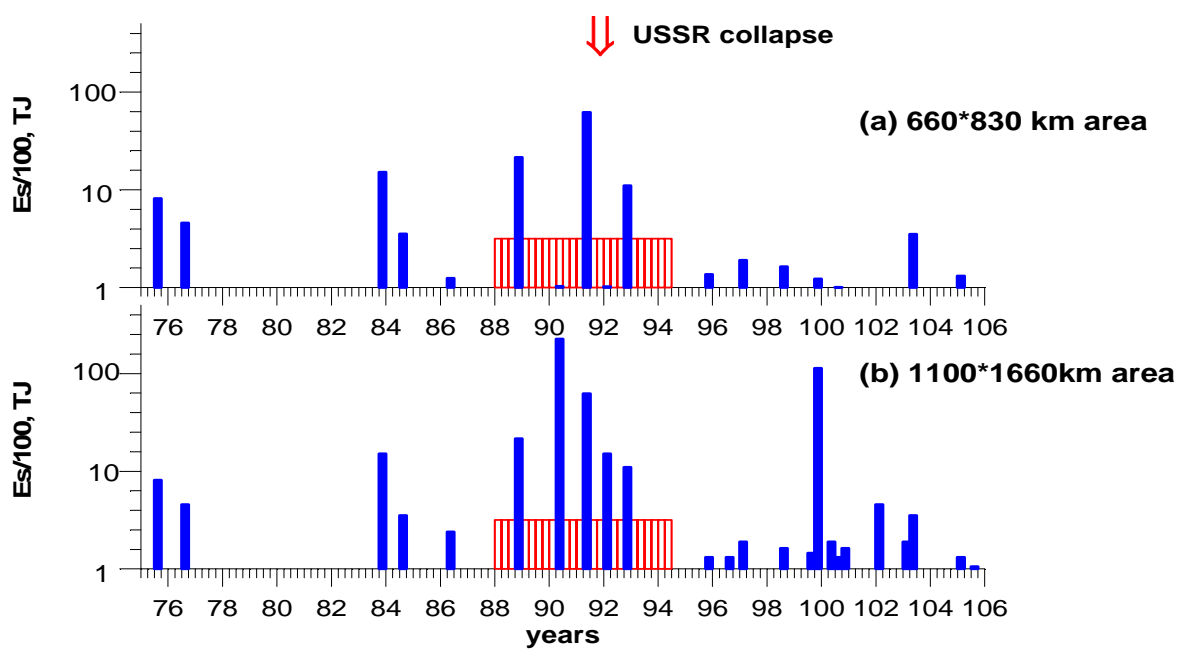

Fig. 1. (a) Seismic energy release in Caucasus area; (b) Energy release in wider area including Caucasus, North Iran and Turkey (see text). Time interval of civil wars in Caucasus is shown by open bars and time of USSR collapse is indicated by arrow.
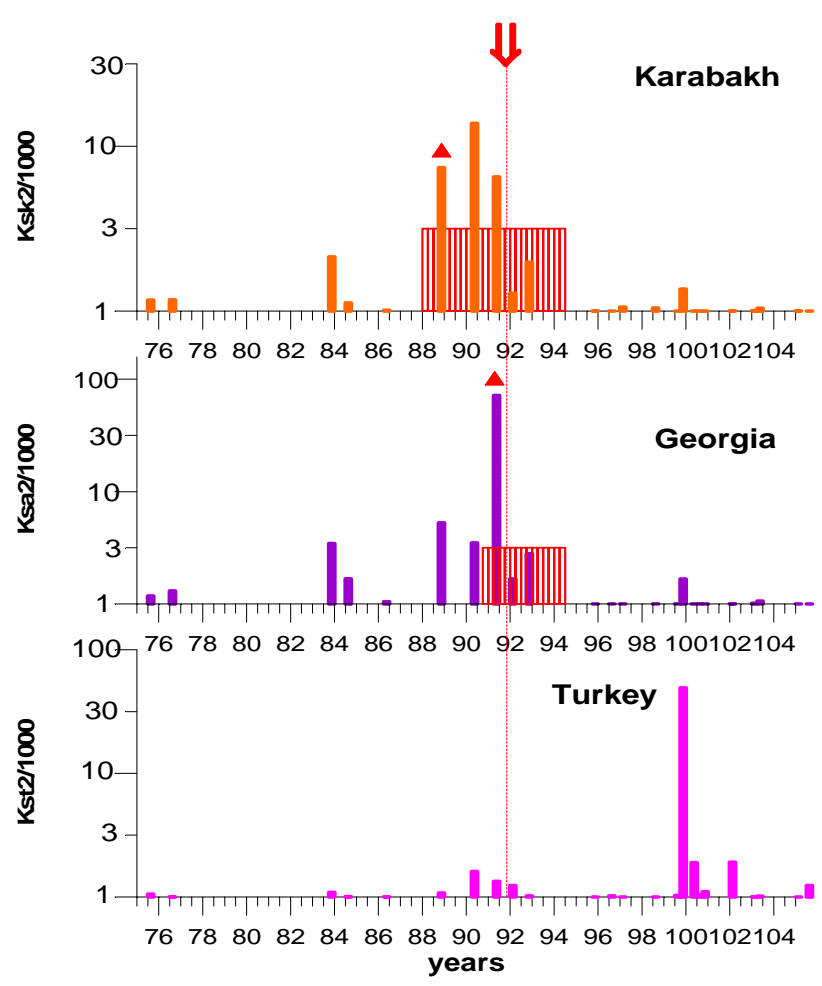

Fig. 2. Normalized quarterly energy release during 30 year from 1975 to 2005 in the determined areas: in the Karabakh (above), in the Western Georgia (middle panel), and in the Turkey (below). Time intervals of the local wars are shown by open bars; damaging EQs in the selected area are marked by triangle.

\subsection{Conflict in Karabakh area}

Until 1987 Karabakh area was the district of Azerbaijan but with majority of Armenian population. Sharp ethnic clashes aiming to join Karabakh to Armenia started at the end of 1987 resulting to announcement of Karabakh authorities on independence of Karabakh from Azerbaijan on 20 February 1988. Everywhere demonstrations, uprisings, killings and massacres both Armenians and Azerbaijanis' population aroused immediately. Only Armenian pogrom at Sumgait town in February 1988 counted hundreds of killed, injured and raped Armenians (e.g. www.openarmenia.com). Intensive partisan war of Karabakh population against Azerbaijani troops continued until the middle of 1992, when large scale Armenia-Azerbaijan war started with participation of about 200 thousands army regular soldiers. The war was stopped by truce in July 1994. So we can define the time interval of the increased social tension from February 1988 to July 1994.

\subsection{Conflict in Western Georgia}

Uprisings in the district South Ossetia have started at the end of 1989 as a reply to racism policy of then-existed Georgia government by Gamsakhurdia under slogan "Georgia for Georgians". Official date of the conflict beginning can be reckoned with announcement of so-called Republic of South Ossetia on 20 September 1990. Military clashes between ethnic Ossetins and Georgia troops began from January 1991. The 18-month civil war in South Ossetia lasted till June 1992. A few thousands peoples were killed and injured during the war (e.g. www.free-osetia.com. However just after truce in South Ossetia the civil war was unleashed in adjacent area of Abkhazia which continued till the middle of 1994. As a result of the civil war two former districts of Georgia, South 


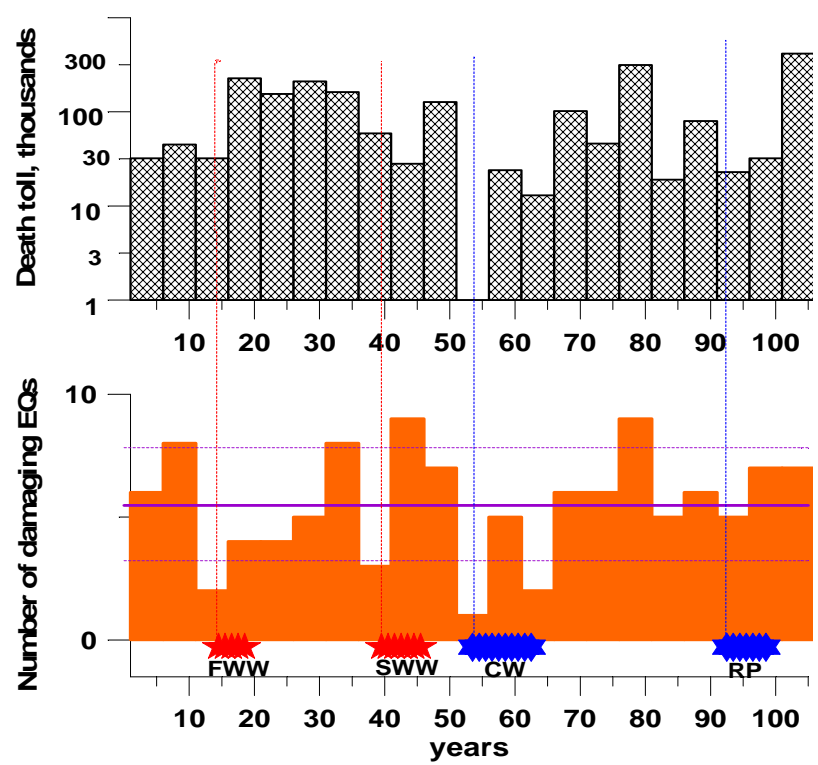

Fig. 3. Death toll of damaging EQs from 1901 to 2005 integrated over 5-year intervals (above) and their number (below). Averaged number is shown by solid line and dispersion margin by dash lines. Intervals of social perturbations are indicated by stars (see text for explanation).

Ossetia and Abkhazia are considered itself as independent states at present. Thus we will define the time interval of military conflict in the Western Georgia from the end of 1990 to the middle of 1994.

Indeed both local war conflicts were in close connection with larger social process, collapse of Soviet Union Empire, which climax can be referred to the end of 1991 .

Other our problem is quantitative estimation of the local EQ activity. A classic approach is counting of EQ number with determined threshold of magnitude $\mathrm{M}$ in selected area or calculation of cumulative seismic energy Es released near epicenter of the EQ:

$E s=10^{1.5(M-M 1)} \mathrm{TJ}$,

where TJ is TeraJoule $=10^{12}$ Joules and $M 1 \approx 4.8$. Note that TJ is about equal to chemical energy of 200 tons of TNT. It means that energy release during Spitak EQ in Armenia $(M=6.9)$ was about equal to 20 Hiroshima-size atomic bomb explosions.

First of all we analyze data from USGS catalog in the Caucasus area (rectangle with Lat. $38-44^{\circ}$, Long. $40-50^{\circ}$ ) and discover that there is no evident change in EQ number related to supposed interval of the social tension. Then presentation of quarterly seismic energy release is given in Fig. 1 for Caucasus area (Fig. 1a) and for wider area (Lat. 34-44, Long. 30-50 ${ }^{\circ}$ including in addition to Caucasus the adjacent seismic active parts of Iran and Turkey (Fig. 1b). The energy values here are normalized to $10^{14} \mathrm{~J}$ that is about energy of Hiroshima atomic bomb as mentioned above.

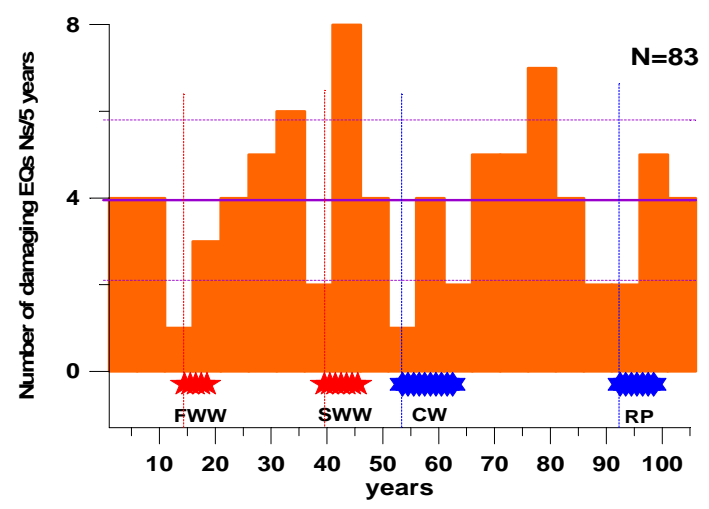

(b)

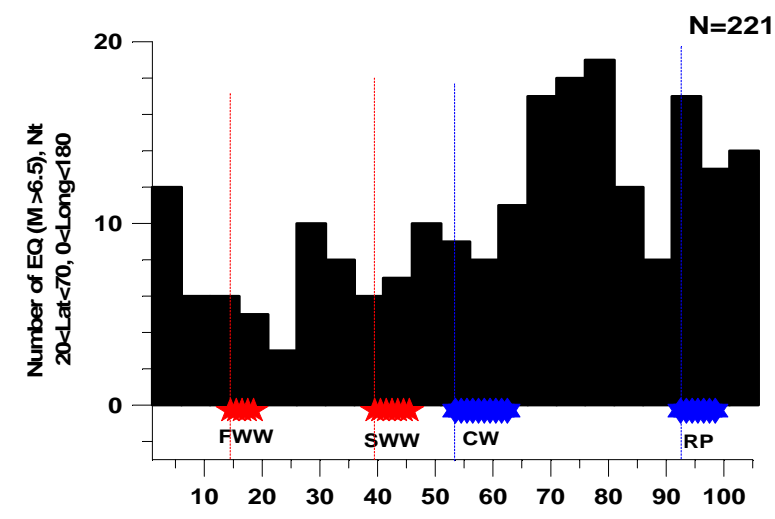

(c)

Fig. 4. (a) Number of global damaging EQs per 5 years; (b) Number of damaging EQs per 5 years in the selected Euro-Asia segment (see text); (c) Number of great EQs $(M>6.5)$ per 5 years in the selected segment.

The correlation in search is also not so convincing and it depends on size of area into consideration.

Another approach is using the index of seismic activity $K s$. This index is proportional to square root of seismic energy transfer into selected point or seismic energy dissipation into selected volume. To be more exact $K s(M, R$, $d) \sim \sqrt{ }(P s * \tau)$, where $P s$ is seismic energy flux taking into account the distance divergence and both elastic and inelastic attenuation of the seismic waves, $\tau$ is duration of seismic pulse in the reception point with distance $R, d$ is depth of EQ hypocenter. It was found that appearance of precursory effects is connected with EQs of large $K s>1$ (see more detailed description of $K s$ index and results of the precursor investigation in the book by Molchanov and Hayakawa (2008).

In the present research we use the value of $K s^{2}$ as energetic measure of EQ activity. We calculate the values for the following points:

a) inside Karabakh area (Lat. $40^{\circ}$, Long. $46^{\circ}$ ),

b) in the middle point between South Ossetia and Abkhazia (Lat. $42.5^{\circ}$, Long. $42.5^{\circ}$ ) and

c) in the Turkey (Lat. $39.8^{\circ}$, Long. $32.8^{\circ}$ ). The last area is chosen as the reference zone. 


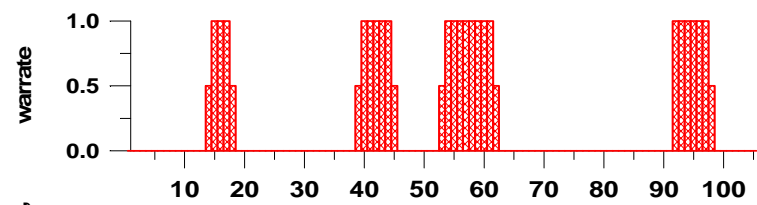

(a)

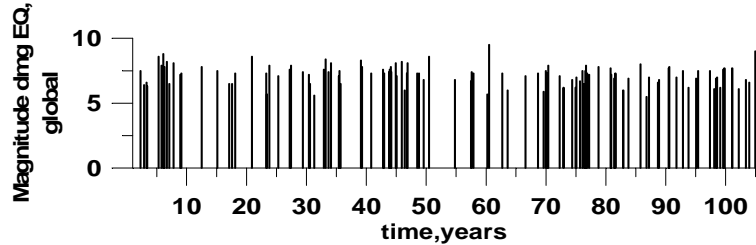

(b)

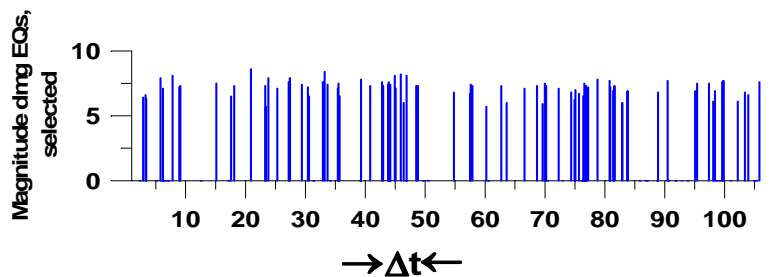

(c)

Fig. 5. (a) Model of war-rate (model w0); (b, c) Magnitude-time distribution of large damaging EQs : over the world (b) and in EuroAsia segment (c). Data are taken from USGS catalog (see Table 1). For finding of correlation parameter, EQ number $N a(t)$ or $N s(t)$, it is necessary to average the real data in some time interval $\Delta t$, which is depicted below.

The results are shown in Fig. 2.

Probably it is not simple coincidence that the local seismic energy input is essentially intensified about 9 months after beginning of war conflict in Karabakh and about 6 months after beginning of civil war in the Western Georgia while the effect is absent in the Turkey reference zone in the same time. Such intensification led to essential damage both in Armenia and Georgia. In Armenia it was famous Spitak EQ, $M=6.9$, on 7 December 1988, where at least 25000 peoples were killed and 19000 were injured. In the Western Georgia it was Racha EQ, $M=7.3$ on 29 April 1991, where at least 114 people were killed, 70 were missing and more than 1000 were injured.

\section{Global statistics of damaging EQs}

Now we take large damaging EQs with death toll more 1000 peoples during last century from beginning 1901 to end of 2005. Their all number is $\mathrm{Na}=115$. We consider them in connection with periods of the great social perturbations as follows:

a) First World War (FWW) which happened from July 1914 to November 1918,

b) Second World War (SWW) from September 1939 to August 1945,

c) Cold War (CW), which, in principle, started from about 1947 and continued until 80th, but escalation and cri-

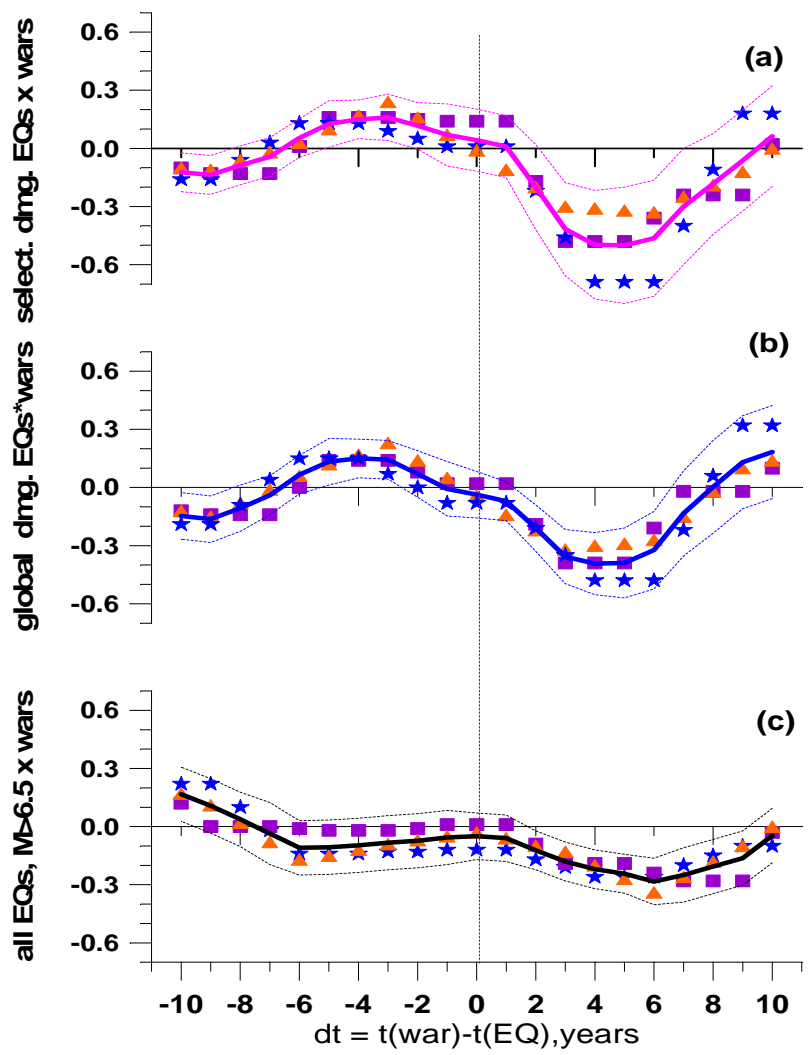

Fig. 6. Correlation of the social perturbations and damaging earthquakes for the 5-year window (stars), 4-year window (squares) and 3 -year window (triangles). Here $d t=t_{w}-t_{E}$, where $t_{w}$ is time of the war perturbation and $t_{E}$ is time of EQ and dash lines are $\pm 2 \sigma$ levels of correlation margin. From above: (a) correlation for selected damaging EQ; (b) correlation for global damaging EQs; (c) correlation for great EQs in mainly unpopulated selected area.

sis period was from 1953 to $1962 \mathrm{http}: / /$ encyclopedia. thefreedictionary.com/Cold+War

d) Restructuring Perturbations in the world system, connected with collapse of the Soviet Union (RP), which sometimes named as the Third World War, from the end of 1991 to the end of 1998 .

Then, supposing some dependence on distance we have chosen the damaging EQs in selected war-prone segment (Lat: 20-70 ${ }^{\circ}$, Long: $0-180^{\circ}$ ) around Euro-Asia continent, $N s=83$. In addition we have considered the great EQs $(M>6.5)$ in selected segment with number $N t=221$. It means that majority of great EQs happened in unpopulated areas.

Global number of damaging EQs and the death toll integrated over 5-year intervals are presented in Fig. 3. It seems there are some correlative changes in Na number during periods of social catastrophes. As shown in Fig. 4, such changes are even more evident for selected damaging EQs, Ns (Fig.4b) and almost absent for total number of the great EQs in selected area, $N t$ (Fig. 4c). 


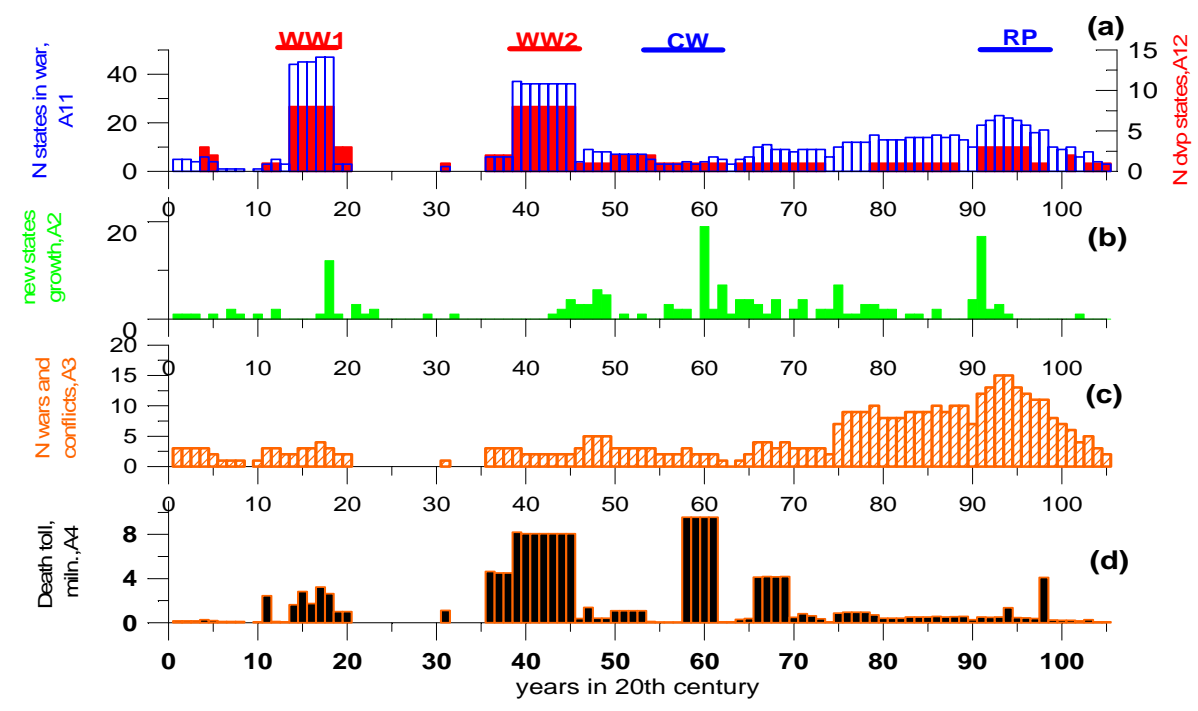

Fig. 7. Distribution of parameters important for estimation of global social tension in the period 1901-2005 years: (a) left scale, open bars: Number of states participated in the war or genocide conflicts, A11; right scale, closed bars: Number of main developed countries, participated in the war conflicts, A12; (b) Number of new independent states, A21; (c) Number of wars and local conflicts, A3; (d) Death toll of war and genocide conflicts (in million peoples/per year), A4.

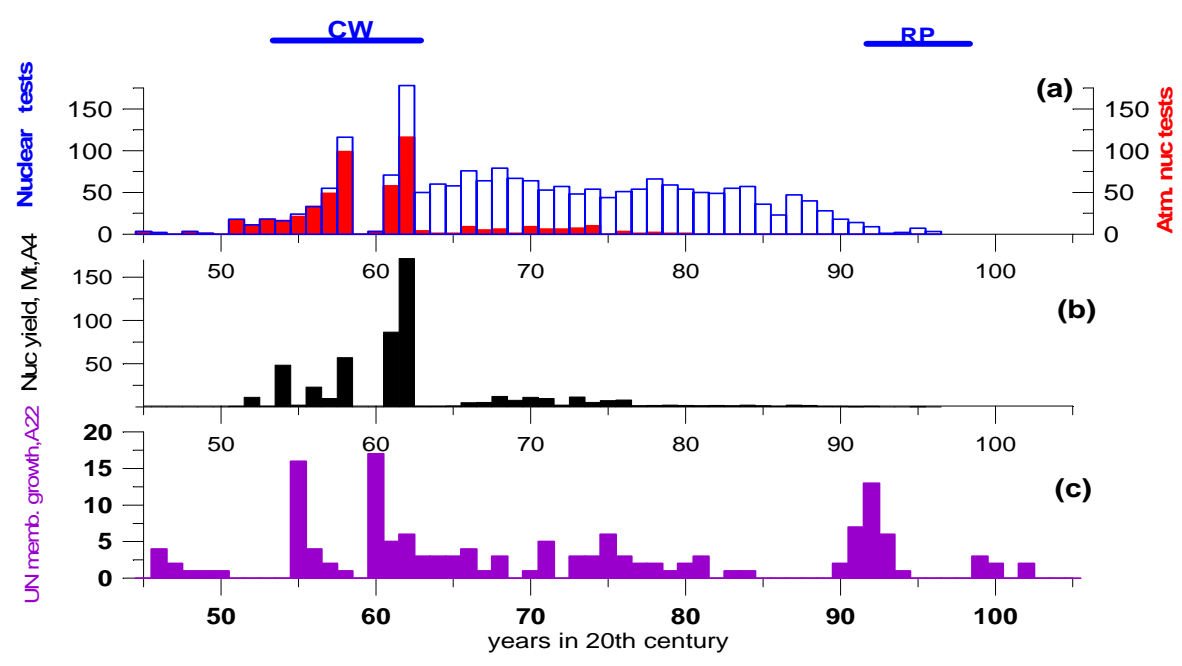

Fig. 8. Distribution of additional parameters important for estimation of global social tension in the period 1945-2005 years. (a) Number of nuclear tests over world (open bars) and separately atmospheric tests (closed bars); (b) Nuclear explosion yield in atmosphere (MegaTon of TNT), A5; (c) Number of new members of UN since foundation, A22.

However we need to check a possible correlation by statistics. Unfortunately we can not apply conventional statistical analysis for finding the averaged time delay between war and seismic events with accuracy of several months:

occurrence rate of damaging EQs is about 1/per year, thus we can not find the delay with time less then 1-2 years. The data presentation is depicted in Fig. 5. For the simplest model (model w0) we simulate the war activity by unit if war time covers the interval or by 0 , if it is outside or by ratio of war time to the interval duration, if war time end is inside the interval.
So, we correlate number of EQ events with occurrence of war events. Conventional procedure is the following:

Firstly, choose the sampling rate with interval $\Delta t$ and create the datasets $n_{\lambda}(i \Delta t), w(i \Delta t), i=[1, N], \lambda=a, s$ or $t$, $N=T_{0} / \Delta t, T_{0}$ is interval of data definition which multiple to $\Delta t$ ( $T_{0} \sim 104$ years in our case). Secondly, exclude the longtime trend that determines the maximal correlation time $T$, value $k_{m}=T /(2 \Delta t)$ and differences $d n_{\lambda}=n_{\lambda}(i \Delta t)-<n_{\lambda}>_{T}$, $d w$. Finally, we need to overcome the ending problems and compute correlation function :

$K(\tau=k \Delta t)=\Sigma d w((i+k) \Delta t) d n_{\lambda}(i \Delta t) /\left(N \sigma_{n} \sigma_{w}\right)$, 


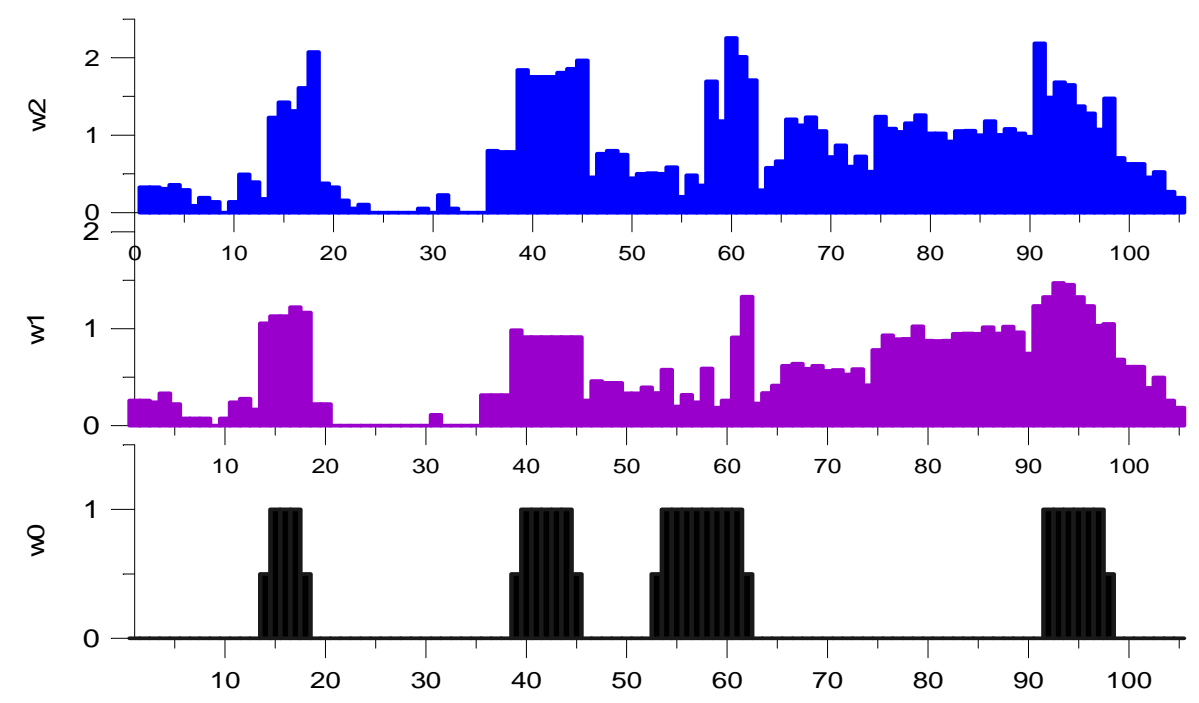

Fig. 9. Model distribution of social tension values during 1901-2005 period (see text).

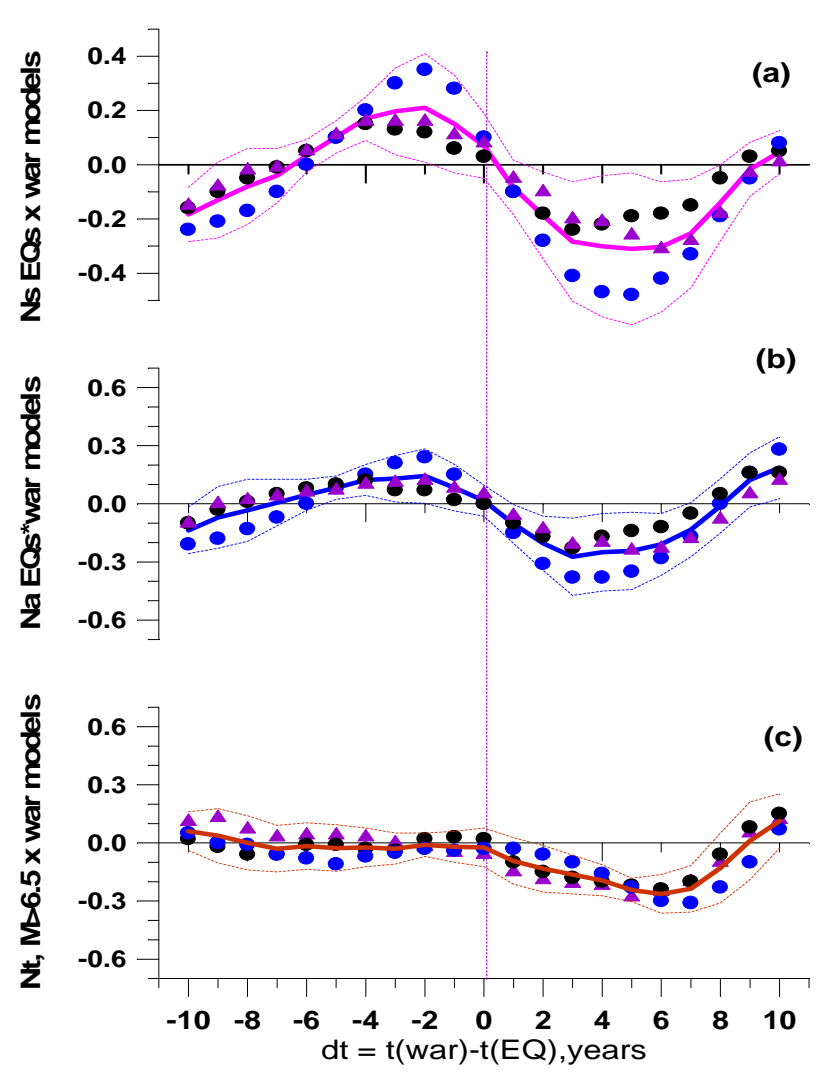

Fig. 10. Dependence of correlation on the model of social tension: w0 (blue circles), w1 (triangles) and w2(black circles, (a) for selected damaging EQs; (b) for global damaging EQs; (c) for great EQs in the selected Euro-Asia segment but mainly in unpopulated area. Dash lines show the margin of reliability ( $\pm 2 \sigma$ levels $)$. where $\tau \leq T / 2$ and $\sigma_{n}, \sigma_{w}$ are dispersion (root mean square) of the data. Indeed, our data are not so good for conventional correlation analysis $(N \sim 20-30)$ and it is necessary to estimate the reliability of the analysis. In this situation the known BSR (boot strap resembling) criteria can be helpful.

The bootstrap is an attractive tool for assessing the accuracy of estimators and testing hypothesis for parameters where conventional techniques are not valid, such as in small data-sample situations (Zoubir and Boashash, 1998). Its meaning is to check correlation for the different division of the dataset. A correlation is considered as significant if its main features are similar for any type of the data set.

There are two possibilities to generate datasets in our case:

a) Change of bin size in $E Q$ dataset.

So we divide the observation period of 105 years in the 5-year intervals (number of intervals $N=21$ ), then in the 4-year intervals $(N=26)$ and in the 3-year intervals $(N=35)$. The results are shown in Fig. 6.

Next type of estimation is as follows:

b) Change of model of social perturbations.

As mentioned above there is no clear definition of the social tension measure especially in global scale, however some parameters could be important, such as number of war conflicts (there were 2 global wars and about 130 local wars during 20th century), number of territorial quarrels or new independent states, number of nuclear tests and so on.

Selected parameters obtained in Internet sites (www. scaruffi.com/politics/massacre.html; http://en.wikipedia. org/wiki/List_of_countries_by_date_of_nationhood;

www.iss.niiit.ru/ksenia/catal_nt/index.htm) are presented in Figs. 7 and 8. 


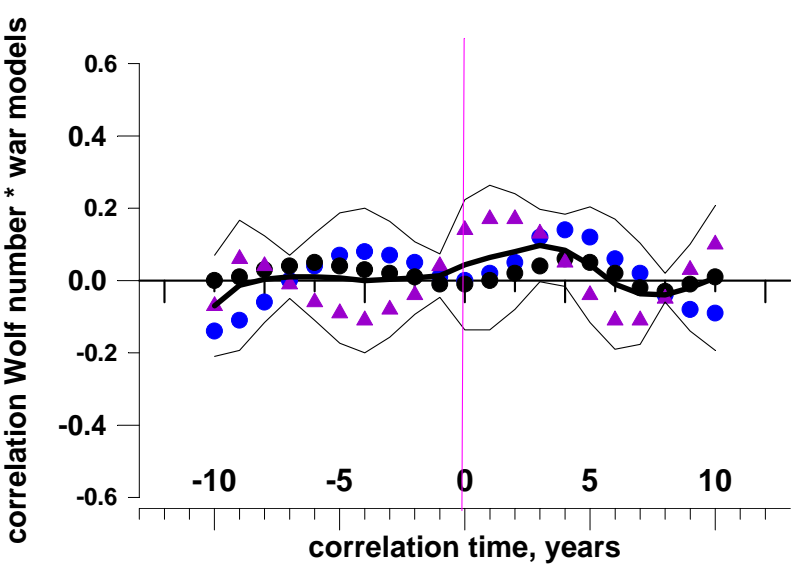

Fig. 11. Correlation of solar activity (Wolf numbers) with social tension using the same models w0, w1, w2 and labels (see Figs. 9, 10) and the same method of computation.

Using selected parameters and numbers from A1 to A5 shown in Figs. 7, 8, we construct two new models of social tension in addition to model $\mathrm{w} 0$ :

$\mathrm{w} 1=(\mathrm{A} 11+\mathrm{A} 12) / \mathrm{A} 1 \max +\mathrm{A} 3 / \mathrm{A} 3 \max +\mathrm{A} 4 / \mathrm{A} 4 \max +\mathrm{A} 5 / \mathrm{A} 5 \max$

$\mathrm{w} 2=\mathrm{w} 1+(\mathrm{A} 21+\mathrm{A} 22 / \mathrm{A} 2 \max )$

These three model distributions are presented in Fig. 9.

Concerning EQ datasets we use current averaging with window 3 years and excluding of long-term trend on $T=23$ years interval. Resulting correlation is shown in Fig. 10.

Similar to the previous estimation method we can see the evident precursory increase in social tension (war activity) and post - seismic decrease related to damaging EQs, but we can not find the same precursory effect for the large EQs in the unpopulated area.

At last we check the correlation method using data on Wolf numbers instead of EQs data.

These Wolf numbers characterize the solar activity and sometimes they are claimed as allegedly connected with social life on the Earth. The result is given in Fig. 11.

Referring to the Fig. 11, sun-social life correlation is absent unlike the result shown in Fig. 6 and Fig. 10.

\section{Discussion}

We conclude:

- There is a statistically reliable increase of social tension several years (or several months in the case study) before damaging EQs,

- There is evident decrease of social tension several years after damaging EQs, probably due to society consolidation,

- Preseismic effect is absent for the large EQs in mainly unpopulated areas.

It is rather difficult to explain the presented evidences by simple coincidence or by some statistical tricks. The second effect, depression of social tension after both damaging EQs and those in unpopulated areas, is rather understandable as sound reaction of community on the natural catastrophe. But to invent a reasonable explanation for the first effect is not easy. From the one hand it reminds a precursor in the abnormal animal behavior (barking of dogs, fast motion of snakes and so on). The difference is only in a time scale: animal perturbations appear several hours or days before EQs but preceding social perturbations are much longer. So, a better sensitivity of complex man community can be speculated to some agent, e.g. to poisoning by rare or radioactive gases, like it was suggested for explanation of the animal precursors. Of course, the simplest explanation is a supervision of some extra-terrestrial force, but unfortunately it can not been accepted as scientific hypothesis. Anyway we need to recognize that there is some factual background for legendary belief in Almighty retribution for social abnormal behavior.

Edited by: P. F. Biagi

Reviewed by: S. Mavrodiev and S. Yunga

\section{References}

Tributsch, H.: When the snakes awake, Cambridge, MIT Press, 1983.

Molchanov, O. and Hayakawa, M.: Seismo-electromagnetics and related phenomena: History and latest results, TERRAPUB, 190 pp., 2008.

Zoubir, A. M. and Boashash, B.: The bootstrap and its application in signal processing, Signal Processing Magazine, IEEE, 15, 5676, 1998. 